\title{
TRANSPHYSEAL FRACTURE FIXATION USING BIODEGRADABLE PINS
}

O. BÖSTMAN, E. A. MÄKELÄ, P. TÖRMÄLÄ, P. ROKKANEN

Internal fixation using biodegradable cylindrical rods of polylactide-glycolide copolymer has been used successfully for displaced malleolar fractures in adults (Rokkanen et al 1985; Böstman et al 1987). In fractures of children internal fixation is infrequently necessary but the advantages of resorbable fixation devices abolishing the need to remove the implants are even more obvious. We report here the early results of transphyseal fracture fixation in six children, the first we have treated with biodegradable polyglycolide pins crossing the growth plate. This method has, to our knowledge, not been previously published.

Experimental study. The present clinical study was preceded by experimental research using radiographic, microradiographic, oxytetracycline fluorescence, histological and histomorphometric techniques. In five-weekold rabbits a drill-hole $2 \mathrm{~mm}$ in diameter across the central portion of the distal growth plate of the femur, destroying $3 \%$ of the plate, caused no growth disturbance, whereas a $3.2 \mathrm{~mm}$ drill-hole, destroying $7 \%$ of the physis, did result in shortening of the femur (Mäkelä et al 1988). Figure 1 shows a biodegradable synthetic polymer pin which was driven into a drill-hole occupying only $3 \%$ of the diameter of the growth plate; at six weeks it has degraded and broken at the plane of the plate. The presence of the implant has not caused any disturbance of growth and the palisading structure of the physis has been restored. The crucial factor seems to be the size of the drill-hole piercing the growth plate (Mäkelä et al 1987).

Clinical study. For the clinical study pins of self-reinforced polyglycolide instead of polylactide-glycolide copolymer were chosen because of better initial strength and strength retention. The pins are $1.5 \mathrm{~mm}$ in diameter, 50 or $60 \mathrm{~mm}$ long; they have an initial shear strength of $250 \mathrm{MPa}$ and a flexural strength of $300 \mathrm{MPa}$.

Supracondylar fractures of the humerus. Three children, aged respectively 7,7 and 9 years, each had an extension

O. Böstman, MD, Orthopaedic Surgeon

E. A. Mäkelä, MD, Orthopaedic Surgeon

P. Rokkanen, MD, Professor and Director

Department of Orthopaedics and Traumatology, Helsinki University Central Hospital, Topeliuksenkatu 5, SF-00260 Helsinki, Finland.

P. Törmälä, PhD, Professor

Biomaterials Laboratory, University of Technology, POB 527, SF33101, Tampere, Finland.

Correspondence to Dr O. Böstman, Tiirasaarentie 11 A 3, SF-00200 Helsinki, Finland.

(C) 1989 British Editorial Society of Bone and Joint Surgery $0301-620 X / 89 / 4 R 19 \$ 2.00$

J Bone Joint Surg [Br] 1989:71-B:706-7

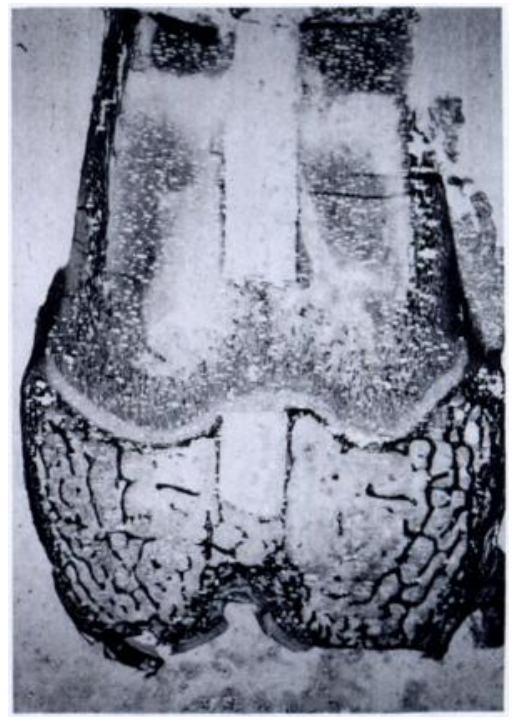

Fig. 1

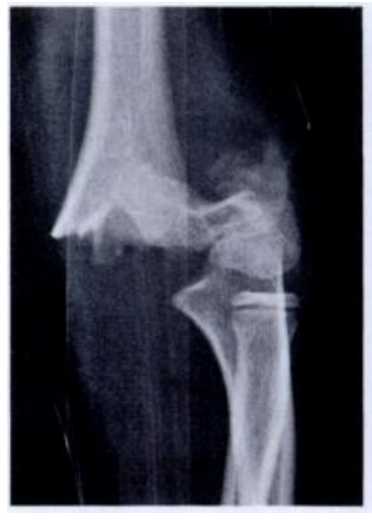

Fig. 2

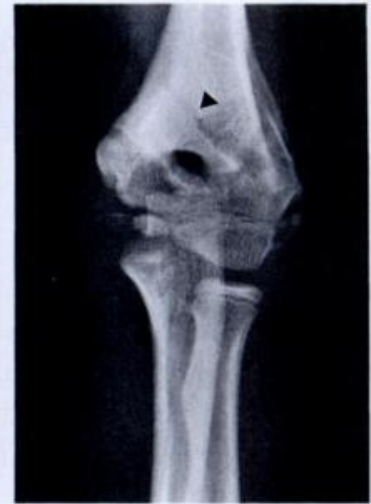

Fig. 3 type of fracture with severe displacement (Fig. 2). Attempted closed reduction failed so the fracture was exposed subperiosteally using a lateral longitudinal incision, and reduced under direct vision. Two channels $1.5 \mathrm{~mm}$ in diameter were drilled transphyseally crosswise through the fracture surfaces, one through the lateral condyle into the proximal fragment and the other through the lateral column of the metaphysis distally into the medial part of the distal fragment. Cylindrical polyglycolide pins $1.5 \mathrm{~mm}$ by 50 or $60 \mathrm{~mm}$ were then tapped into these channels to fix the fracture. A plaster-cast with the elbow at $90^{\circ}$ and the forearm in midrotation was worn for four weeks.

After 5 to 10 months two of the patients had no significant change in the carrying angle and full movement of the elbow joint. The radiograph in Figure 3 was 
taken after eight months; the fracture has healed uneventfully and the channel drilled from the lateral condyle into the metaphysis is still visible (arrow). In the third patient, radiographs at one week had shown a medial tilt of the distal fragment (after an initially anatomical reduction and fixation) and this resulted in a varus deformity of $10^{\circ}$.

Physeal fractures. Three patients have been treated: an eight-year-old boy with a markedly displaced SalterHarris Type II fracture at the proximal physis of the first metatarsal bone, a 14-year-old boy with a displaced Salter-Harris Type III fracture at the distal tibial physis; and a 13-year-old boy, with an avulsed displaced medial epicondyle of the humerus. In each case the fracture was exposed, reduced and fixed with two transphyseal pins. Protective plaster was worn for a few weeks and recovery was uneventful.

Discussion. To assess the applicability of biodegradable transphyseal pins for fixing fractures in children two questions must be considered. First, is it absolutely certain that they will not disturb growth? This question obviously cannot be definitively answered until the patients have reached skeletal maturity. However, the cross-sectional area of an $1.5 \mathrm{~mm}$ pin is only $1.8 \mathrm{~mm}^{2}$; consequently, in supracondylar fractures of the humerus and in physeal injuries of the distal tibia even in small children, the use of two such pins clearly falls within the experimentally observed safe limit of $3 \%$ of the growth plate (Mäkelä et al 1988). In our clinical study with follow-up times of up to 10 months no signs of impairment of physeal function emerged. Secondly, will the pins hold reduction securely until the fracture has united? Our preliminary experience indicates that this demand can be met in most cases, though the surgical technique needs to be even more precise than when metal pins are used.

Because they are biodegradable and do not need to be removed, polyglycolide pins are an attractive alternative to Kirschner wires for fractures which need transphyseal internal fixation.

Although none of the authors have received or will receive benefits for personal or professional use from a commercial party related directly or indirectly to the subject of this article, benefits have been or will be received but are directed solely to a research fund, foundation, educational institution, or other non-profit institution with which one or more of the authors is associated.

\section{REFERENCES}

Böstman O, Vainionpää S, Hirvensalo E, et al. Biodegradable internal fixation for malleolar fractures: a prospective randomised trial. $J$ Bone Joint Surg [ Br] 1987;69-B :61 5-9.

Mäkelä EA, Vainionpää S, Vihtonen K, et al. The effect of a penetrating biodegradable implant on the epiphyseal plate: an experimental study on growing rabbits with special regard to polyglactin $910 . J$ Pediatr Orthop 1987:7:415-20.

Mäkelä EA, Vainionpää S, Vihtonen $K$, Mero M, Rokkanen $P$. The effect of trauma to the lower femoral epiphyseal plate: an experimental study in rabbits. J Bone Joint Surg [Br] 1988:70B:187-91.

Rokkanen P, Böstman O, Vainionpää S, et al. Biodegradable implants in fracture fixation: early results of treatment of fractures of the ankle. Lancet 1985.1422-4.

\title{
THE NATURAL HISTORY OF GANGLIA IN CHILDREN
}

\author{
JOHN W. ROSSON, GEOFFREY WALKER
}

Although an understanding of the natural history of a condition is an essential prerequisite for logical treatment, little has been published on the natural history of simple ganglia in children. At Queen Mary's Hospital for Children, it has been the practice to treat asymptomatic ganglia expectantly, provided the diagnosis can be confirmed by transillumination. This present study was undertaken to determine whether or not this approach has been justified.

Patients. The hospital records revealed 63 patients under the age of 16 years presenting with ganglia. Of these, 16 were known to have been treated surgically elsewhere or at Queen Mary's Hospital, if significant symptoms had

J. W. Rosson, FRCS, Registrar

G. Walker, FRCS, Senior Consultant

Queen Mary's Hospital for Children, Carshalton, Surrey SM5 4NR, England.

Correspondence to Mr J. W. Rosson at 33d Aldridge Road Villas, London WII IBN, England.

(C) 1989 British Editorial Society of Bone and Joint Surgery $0301-620 X / 89 / 4 \mathrm{R} 25 \$ 2.00$

J Bone Joint Surg [Br] 1989:71-B:707-8. developed or there had been doubt about the diagnosis. Of the remaining 47 it was possible to contact 29 , all of whom had remained untreated, and these formed the basis of this study. The mean age of the children was 7.5 years at presentation (range 6 months to 15 years): 17 were girls and 12 boys; 15 ganglia occurred at the wrist, 11 on the foot and three on the hand.

Results. At review, 22 of the ganglia had disappeared spontaneously while seven remained. The mean followup was 5.5 years for those that had resolved and 3.75 years for those that were still present. The mean estimated duration of the ganglia prior to spontaneous resolution was 10.5 months (range 1 month to 4.5 years), only two persisting for more than two years (Table I). Of the seven that remained, six had been present for in excess of two years.

Discussion. The natural history of children with untreated ganglia is difficult to study. The low incidence of the condition among children (Nelson, Sawmiller and Phalen 1972), the mobility of the population and the tendency for children to be taken elsewhere for surgery all militate against a large series. In 1977 MacCollum reported on 14 